\title{
FAKTOR-FAKTOR YANG BERHUBUNGAN DENGAN KONSENTRASI SIANIDA DALAM URIN MASYARAKAT KAWASAN PESISIR
}

\author{
THE FACTORS RELATED TO CYANIDE CONSENTRATION \\ IN URINE OF COASTAL COMMUNITY
}

\author{
Tri Septian Maksum \\ Fakultas Olahraga dan Kesehatan, Universitas Negeri Gorontalo \\ E-mail: triseptian@ung.ac.id
}

\begin{abstract}
ABSTRAK
Sianida $(\mathrm{CN})$ termasuk dalam golongan bahan pencemar yang sering mencemari perairan dan berdampak pada manusia apabila mengkonsumsi biota dari perairan tersebut. Penelitian ini bertujuan mengetahui faktor-faktor yang berhubungan dengan konsentrasi $\mathrm{CN}$ urin masyarakat pesisir Desa Mallasoro Kecamatan Bangkala Kabupaten Jeneponto. Penelitian ini merupakan jenis penelitian observasional menggunakan rancangan cross sectional. Sampel kerang hijau masing-masing diambil pada tujuh titik lokasi menggunakan teknik grab sample, sedangkan sampel urin diambil pada tiga puluh responden secara purposif. Data dikumpulkan melalui wawancara dan hasil pemeriksaan laboratorium menggunakan metode UV-Vis Spektrofotometri. Data dianalisis menggunakan uji korelasi Spearman dan regresi linier berganda. Hasil penelitian menunjukkan bahwa variabel yang berhubungan dengan konsentrasi $\mathrm{CN}$ dalam urin responden adalah konsentrasi $\mathrm{CN}$ dalam kerang hijau $(\mathrm{p}=0.000, \mathrm{r}=0.612)$, lama tinggal $(\mathrm{p}=0.001, \mathrm{r}=0.594)$, lama konsumsi kerang hijau $(\mathrm{p}=0.000, \mathrm{r}=0.703)$, dan frekuensi konsumsi singkong $(\mathrm{p}=0.011, \mathrm{r}=0.457)$. Variabel yang tidak berhubungan yaitu: umur $(\mathrm{p}=0.578, \mathrm{r}=-$ $0.106)$, dan jumlah konsumsi rokok per hari ( $\mathrm{p}=0.224, \mathrm{r}=0.229)$. Namun, variabel yang menjadi prediktor terhadap konsentrasi $\mathrm{CN}$ dalam urin adalah konsentrasi CN dalam kerang hijau, lama konsumsi kerang hijau, dan frekuensi konsumsi singkong, dengan model regresi yang diperoleh $\mathrm{Y}=-11,426+33,662 \mathrm{X}_{1}+0,046 \mathrm{X}_{2}+0,667 \mathrm{X}_{3}$. Disarankan kepada masyarakat pesisir Desa Mallasoro untuk mengurangi atau bahkan tidak lagi mengkonsumsi kerang hijau dari perairan tersebut dan melakukan pengolahan yang tepat pada singkong sebelum dikonsumsi yakni dengan cara pencucian, perendaman atau perebusan, sehingga menjadi aman untuk dikonsumsi.
\end{abstract}

Kata kunci: Sianida, Kerang Hijau, Urin, Pesisir

\begin{abstract}
Cyanide $(C N)$ belong to a class of pollutants that often contaminate the waters and they could affect humans when consuming biota from this water. The aim of the research was to analyze the factors related to $C N$ consentration in urine of coastal community in Mallasoro Village of Bangkala District, Jeneponto Regency. The study was an observational method with crosssectional design. The samples of green mussel were taken at the point location using grab sample technique and the sample of urine was taken from 30 respondents using purposive sampling technique. The data were obtained through interview and the results of laboratory test using UV-Vis Spectrophotometry. They were analyzed using Spearman's correlation and multiple linear regression. The results of the research indicate that the variables related to $C N$ consentration in urine are $C N$ consentration in green mussel ( $p=0.000, r=0.612)$, length of stay $(p=0.001, r=0.594)$, duration of green mussel consumption $(p=0.000$, $r=0.703)$, and frequency of cassava consumption $(p=0.011, r=0.457)$. The unrelated variables are age $(p=0.578$, $r=-0.106)$ and total daily cigarette consumption $(p=0.224, r=0.229)$. However, the predictor variables to $C N$ consentration in urine are $C N$ consentration in green mussel, duration of green mussel consumption, and frequency of cassava consumption with the obtained regression model obtained of $Y=-11.426+33.662 X_{1}+$ $0.046 X_{2}+0.667 X_{3}$. It was suggested to the coastal communities at Mallasoro Village to reduce or no longer consume the green mussel from the waters and to do the proper processing on cassava before consumed by washing, soaking or boiling, so it is safe for consumption.
\end{abstract}

Keywords: Cyanide, Green Mussel, Urine, Coastal 


\section{PENDAHULUAN}

senyawa non logam yang berbahaya dan sering mencemari lingkungan perairan adalah sianida. Sianida dapat berbentuk gas, cair, atau padat dan berbentuk molekul, ion, atau polimer. Semua bahan yang dapat melepaskan ion sianida $\left(\mathrm{CN}^{-}\right)$sangat toksik (Kamilah dkk., 2014).

Sianida dapat terakumulasi dalam sedimen. Sedimen merupakan lapisan bawah yang melapisi sungai, danau, reservoar, teluk, muara, dan lautan (Siaka, 2008). Sianida yang mengendap di dasar perairan mempunyai waktu tinggal (residence time) sampai ribuan tahun dan akan terkonsentrasi ke dalam tubuh makhluk hidup melalui proses bioakumulasi dan biomagnifikasi dan masuk melalui inhalasi (saluran pernapasan), oral (makanan dan minuman) dan kontak kulit (Darmono, 2010).

Biota yang menjadi indikator adanya pencemaran di perairan salah satunya adalah kerang hijau (Susanty, 2014). Sianida yang terkonsumsi oleh kerang hijau akan membahayakan manusia yang mengkonsumsinya (Simange dkk., 2010). Hasil penelitian Cordos et al (2003), sedimen di perairan Baia Mare, Romania mengandung sianida yang tinggi yakni 0,33-15,86 $\mathrm{mg} / \mathrm{kg}$, menyebabkan jumlah spesies ikan menurun drastis dibandingkan dengan periode sebelum terjadi kasus dan banyak spesies moluska (termasuk kerang) tidak terlihat lagi. Penelitian sejenis lainnya seperti Kasus Minamata di Jepang tahun 1955-1960 akibat pencemaran merkuri yang berasal dari limbah industri plastik yang dibuang ke dalam perairan (Teluk Minamata). Kandungan merkuri ikan di sekitar Teluk Minamata sebesar 9-24 ppm yang kemudian dikonsumsi oleh masyarakat yang mengakibatkan 110 orang meninggal (Mangampe dkk., 2014).
Beberapa kasus di Indonesia antara lain di Perairan Teluk Buyat, Sulawesi Utara dimana sejak tahun 1996 perairan tersebut telah dijadikan tempat pembuangan tailing oleh PT. Newmont Minahasa Raya, akibatnya masyarakat yang mengkonsumsi ikan di sekitar Teluk Buyat mengalami gangguan kesehatan terutama penyakit kulit (Widowati dkk., 2008). Penelitian sejenis juga pernah dilakukan di Pesisir Makassar, diperoleh konsentrasi merkuri pada sedimen laut, ikan dan kerang tertinggi di Kelurahan Cambayya. Tingkat risiko konsumsi ikan dan kerang yang mengandung merkuri menunjukkan bahwa semua responden berisiko (RQ>1) (Ishak, 2014).

Isu kesehatan lingkungan yang cukup serius pada periode 31 Agustus - 3 September 2016 adalah keracunan makanan di Desa Mallasoro Kecamatan Bangkala Kabupaten Jeneponto akibat mengkonsumsi kerang. Berdasarkan Laporan dari Dinas Kesehatan Kabupaten Jeneponto bahwa jumlah penderita yang mengalami keracunan sebanyak 63 orang dan 3 orang diantaranya meninggal. Gejala klinisnya berupa sakit perut, mual, muntah, diare, pusing, sakit kepala, kejang, ruam biru pada tubuh dan rasa baal di mulut. Hasil pemeriksaan BPOM Makassar pada sampel sisa kerang yang telah dikonsumsi dan kerang mentah yang belum diolah menunjukkan positif sianida (Dinas Kesehatan Provinsi Sulawesi Selatan, 2016).

Kadar sianida dalam urin adalah salah satu indikator yang digunakan untuk menilai sejauh mana kontaminasi bahan pencemar tersebut terjadi pada manusia. Menurut Oesch (2010), kadar sianida normal dalam urin berdasarkan National Medical Services, United States adalah 2 $\mu \mathrm{g} / 100 \mathrm{ml})$. Faktor-faktor yang dapat 
mempengaruhi konsentrasi sianida dalam urin antara lain umur, jumlah konsumsi rokok/hari; lama tinggal; konsentrasi sianida dalam kerang hijau yang dikonsumsi, lama konsumsi kerang hijau (Siagian, 2012); dan frekuensi konsumsi bahan makanan yang mengandung sianida alami (Ningtyias dkk., 2015).

Berdasarkan uraian tersebut, maka penelitian ini bertujuan untuk menganalisis faktor-faktor yang berhubungan dengan konsentrasi sianida $(\mathrm{CN})$ dalam urin masyarakat pesisir Desa Mallasoro Kecamatan Bangkala Kabupaten Jeneponto.

\section{METODE PENELITIAN}

Penelitian ini dilakukan di wilayah pesisir Desa Mallasoro, Kecamatan Bangkala, Kabupaten Jeneponto. Jenis penelitian adalah penelitian observasional dengan desain cross sectional. Populasi dalam penelitian ini terbagi atas dua yaitu populasi lingkungan dan manusia. Populasi lingkungan yaitu seluruh kerang hijau yang ada di perairan pesisir Desa Mallasoro Kecamatan Bangkala. Populasi manusia yaitu seluruh masyarakat yang tinggal dan mengalami keracunan makanan pada periode 31 Agustus - 3 September 2016 di desa tersebut, yakni sebanyak 60 orang.

Sampel kerang hijau masing-masing diambil pada 7 titik lokasi menggunakan teknik grab sample atau sampel sesaat, yaitu salah satu teknik dalam pengambilan sampel lingkungan, yang cara pengambilannya dilakukan secara langsung dari badan air yang sedang dipantau. Sampel manusia menggunakan teknik purposive sampling sehingga diperoleh besar sampel 30 orang, dengan memperhatikan kriteria inklusi yaitu masyarakat Desa Mallasoro yang bermukim dan menetap secara terus menerus selama $>5$ tahun, masih mengkonsumsi kerang hijau dari perairan tersebut dan bersedia menjadi responden.

Pengumpulan data terdiri dari data primer dan data sekunder. Data primer diperoleh dari hasil pemeriksaan laboratorium dan wawancara menggunakan kuesioner, sedangkan data sekunder diperoleh dari Dinas Kesehatan Provinsi Sulawesi Selatan. Analisis data dilakukan dengan bantuan program SPSS versi 20. Analisis univariat menggambarkan karakteristik semua variabel dalam bentuk tabel distribusi frekuensi, analisis bivariat menggunakan uji korelasi spearman dan analisis multivariat menggunakan uji regresi linier berganda. Penyajian data dalam bentuk tabel dan disertai narasi.

\section{HASIL DAN PEMBAHASAN}

\subsection{Hasil}

Konsentrasi $\mathrm{CN}$ dalam kerang hijau berkisar 0,392 - 0,867 ppm dengan nilai tengah (median) yaitu 0,409. Konsentrasi $\mathrm{CN}$ dalam kerang hijau masih dalam batasan aman menurut FAO/WHO yakni $1,0 \mathrm{mg} / \mathrm{kg}$ atau $1,0 \mathrm{ppm}$. Konsentrasi $\mathrm{CN}$ dalam urin responden berkisar 2,592 7,128 ppm dengan nilai median yakni 5,184 ppm, yang berarti semua responden telah melebihi batas toleransi yang ditetapkan oleh National Medical Services, United States yaitu $2 \mu \mathrm{g} / 100 \mathrm{ml}$ atau 0,02 ppm (Tabel 1). 


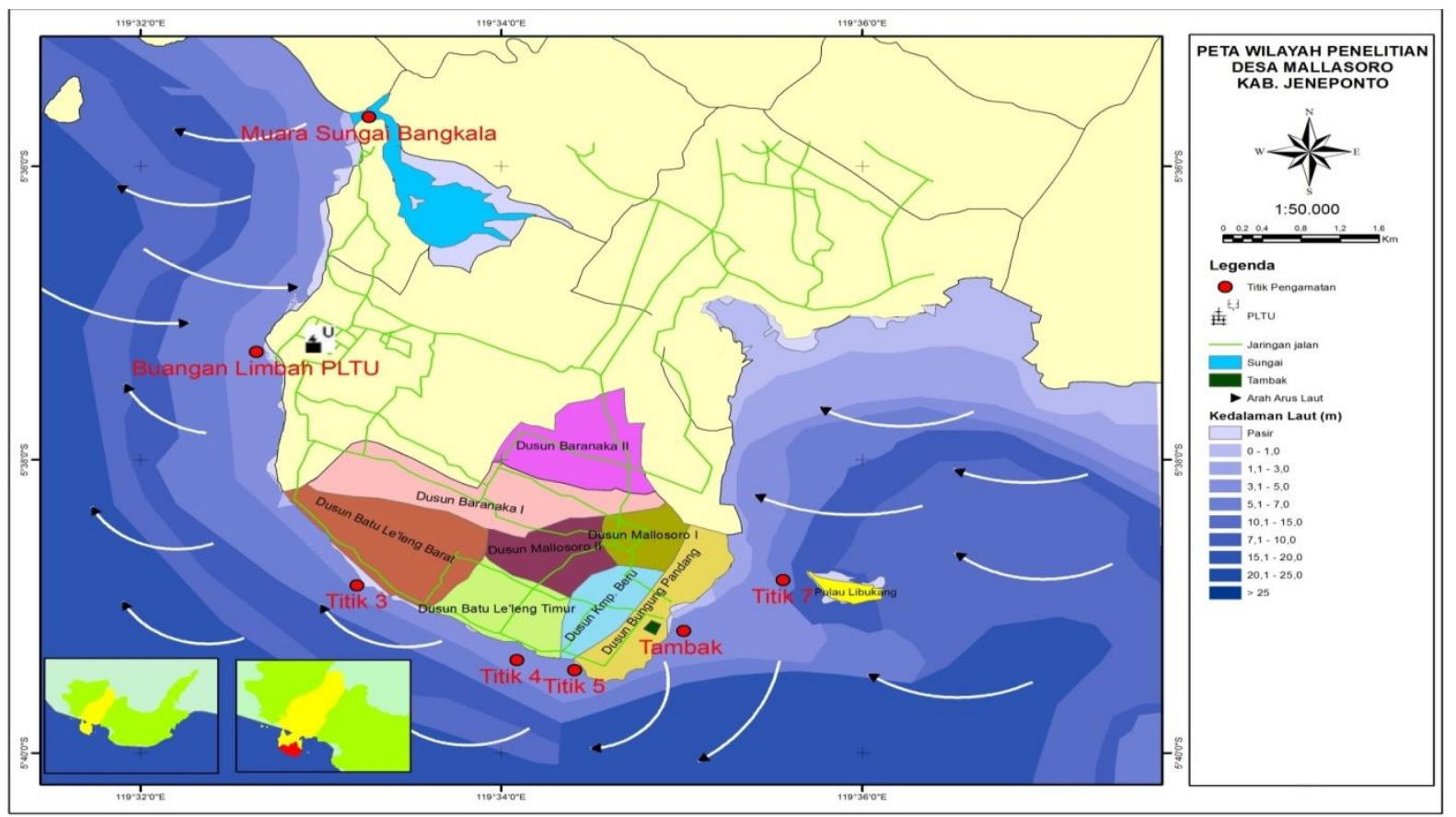

Gambar 1. Peta Lokasi Penelitian

Tabel 1. Konsentrasi CN dalam Kerang Hijau dan Urin Masyarakat Pesisir

\begin{tabular}{cccc}
\hline Bahan Pencemar & Min & Max & Median \\
& & & 0,409 \\
CN dalam kerang hijau & 0,392 & 0,867 & 5,184 \\
CN dalam urin & 2,592 & 7,128 & \\
\hline
\end{tabular}

Sumber: Data Primer, 2017

Tabel 2. Karakteristik Responden

\begin{tabular}{ccc}
\hline Karakteristik Responden & $\mathrm{n}$ & $\%$ \\
\hline Jenis kelamin & & \\
Laki-laki & 15 & 50,0 \\
Perempuan & 15 & 50,0 \\
Kelompok umur (tahun) & & \\
$20-29$ & 3 & 10,0 \\
$30-39$ & 6 & 13,3 \\
$40-49$ & 4 & 56,7 \\
$\geq 50$ & 17 & 0,0 \\
Lama tinggal (tahun) & 0 & 100,0 \\
$\leq 5$ & 30 & \\
$>5$ & & 90,0 \\
Kebiasaan mengkonsumsi kerang hijau & & 10,0 \\
Frekuensi konsumsi (kali/minggu) & 27 & 63,3 \\
$\leq 5$ & 3 & 36,7 \\
$>5$ & & \\
Jumlah konsumsi (gram/minggu) & 19 & 0,0 \\
$\leq 100$ & 11 & 100,0 \\
$>100$ & & \\
Lama Konsumsi (tahun) & & 0,0 \\
$>5$ & 30 & 100,0
\end{tabular}




\begin{tabular}{ccc}
\hline Karakteristik Responden & $\mathrm{n}$ & $\%$ \\
\hline Jumlah konsumsi rokok (batang/hari) & 2 & 16,7 \\
$1-6$ & 1 & 8,3 \\
$7-12$ & 9 & 75,0 \\
$>12$ & & \\
Kebiasaan mengonsumsi singkong & 23 & 100,0 \\
Frekuensi konsumsi (kali/minggu) & 0 & 0,0 \\
$\leq 5$ & & 60,9 \\
$>5$ & 14 & 39,1 \\
Jumlah konsumsi (gram/minggu) & 9 & 0,0 \\
$\leq 100$ & & 100,0 \\
$>100$ & 0 & \\
Lama konsumsi(tahun) & 23 & \\
$\leq 5$ & & \\
$>5$ & & \\
\hline
\end{tabular}

Sumber: Data Primer, 2017

Tabel 2 menunjukkan bahwa jika dilihat dari segi umur, maka responden terbanyak berada pada kelompok umur $\geq 50$ tahun (lansia) yakni $17(56,7 \%)$ orang dan paling sedikit pada kelompok umur $20-29$ tahun yakni $3(10,0 \%)$ orang. Responden dalam penelitian ini memiliki jumlah yang sama antara laki-laki dan perempuan yaitu masing-masing 15 (50,0\%) orang. Seluruh $(100,0 \%)$ responden bermukim di lokasi penelitian dengan lama $>5$ tahun.

Kebiasaan mengkonsumsi kerang hijau dapat dilihat dari status konsumsi, frekuensi dan jumlah konsumsi per minggu, lama konsumsi serta tempat memperoleh kerang hijau tersebut. Dapat diketahui bahwa seluruh $(100,0 \%)$ responden mengkonsumsi kerang hijau sebagai lauk. Responden paling banyak 27 (90,0\%) orang mengkonsumsi $\leq 5 \mathrm{kali} / \mathrm{ming} g u$ dan sisanya $3(10,0 \%)$ orang dengan frekuensi $>5$ kali/minggu. Kerang hijau yang dikonsumsi paling banyak $\leq 100$ gram/minggu yakni 19 $(63,3 \%)$ dan sedikitnya $11(36,7 \%)$ orang dengan jumlah > 100 gram/minggu. Seluruh $(100,0 \%) \quad$ responden telah mengkonsumsinya selama $>5$ tahun.
Kebiasaaan merokok dapat dilihat dari status merokok, lama dan jumlah konsumsi rokok. Paling banyak responden tidak merokok yaitu $18(60,0 \%)$ orang dan merokok hanya 12 (40,0\%) orang. Seluruh responden (perokok) telah merokok selama> 5 tahun. Jumlah rokok yang dikonsumsi paling banyak > 12 batang/hari yakni $9(75,0 \%)$ orang dan paling sedikit 1 $(8,3 \%)$ orang dengan jumlah $7-12$ batang/hari.

Kebiasaan mengkonsumsi singkong dapat dilihat dari status konsumsi, frekuensi dan jumlah konsumsi per minggu serta lama konsumsinya. Paling banyak responden mengkonsumsi singkong yakni 23 (76,7\%) orang dan yang tidak mengkonsumsi hanya $7(23,3 \%)$ orang. Seluruh $(100,0 \%)$ responden mengkonsumsi singkong dengan jumlah $\leq 5 \mathrm{kali} /$ minggu. Paling banyak responden yang mengkonsumsinya dengan jumlah $\leq 100$ gram/minggu yakni 14 $(60,9 \%)$ orang dan paling sedikit $9(39,1 \%)$ orang dengan jumlah > 100 gram/minggu. Seluruh $(100,0 \%)$ responden telah mengkonsumsi singkong selama> 5 tahun. 
Tabel 3. Hubungan antara Berbagai Faktor dengan Konsentrasi CN dalam Urin Masyarakat Pesisir

\begin{tabular}{|c|c|c|c|c|}
\hline Variabel & p-value & $\mathrm{r}$ & Kesimpulan & Kekuatan korelasi \\
\hline $\begin{array}{l}\mathrm{CN} \text { dalam kerang hijau* } \mathrm{CN} \\
\text { dalam urin }\end{array}$ & 0.000 & 0.612 & Ada korelasi & Kuat \\
\hline Umur* $\mathrm{CN}$ dalam urin & 0.578 & -0.106 & Tidak ada korelasi & Sangat lemah \\
\hline Lama tinggal $* \mathrm{CN}$ dalam urin & 0.001 & 0.594 & Ada korelasi & Cukup kuat \\
\hline $\begin{array}{l}\text { Lama konsumsi kerang hijau* } \\
\text { CN dalam urin }\end{array}$ & 0.000 & 0.703 & Ada korelasi & Kuat \\
\hline $\begin{array}{l}\text { Jumlah konsumsi rokok/hari* } \\
\text { CN dalam urin }\end{array}$ & 0.224 & 0.229 & Tidak ada korelasi & Lemah \\
\hline $\begin{array}{c}\text { Frekuensi Konsumsi } \\
\text { Singkong* CN dalam urin }\end{array}$ & 0.011 & 0.457 & Ada korelasi & Cukup kuat \\
\hline
\end{tabular}

Sumber: Data Primer, 2017

Tabel 3 menunjukkan hasil uji korelasi spearman antara konsentrasi $\mathrm{CN}$ dalam kerang hijau, lama tinggal, lama konsumsi kerang hijau dan frekuensi konsumsi singkong dengan konsentrasi $\mathrm{CN}$ dalam urin, diperoleh nilai $\mathrm{p}$ berturut-turut adalah 0.000, 0.001, 0.000 dan 0.011 (p < $0,05)$ serta nilai $r$ berturut-turut 0.612 , 0.594, 0.703 dan 0.457. Disimpulkan bahwa ada hubungan yang signifikan antara konsentrasi $\mathrm{CN}$ dalam kerang hijau, lama tinggal, lama konsumsi kerang hijau dan frekuensi konsumsi singkong dengan konsentrasi $\mathrm{CN}$ dalam urin. Kekuatan hubungan ke empat variabel tersebut dengan konsentrasi $\mathrm{CN}$ dalam urin berturutturut adalah kuat, cukup kuat, kuat dan cukup kuat. Koefisien korelasi ke empat variabel bernilai positif yang artinya menunjukkan hubungan yang searah. Semakin tinggi konsentrasi sianida dalam kerang hijau, semakin lama responden tinggal, semakin lama responden mengkonsumsi kerang hijau dan semakin tinggi frekuensi konsumsi singkong maka konsentrasi sianida dalam urin juga akan semakin meningkat.

Variabel umur dan jumlah konsumsi rokok/hari terhadap konsentrasi $\mathrm{CN}$ dalam urin diperoleh nilai $\mathrm{p}$ berturut-turut 0.578 dan $0.224(\mathrm{p}>0,05)$ serta nilai $r$ berturutturut-0,106 dan 0,229. Hasil uji statistik ini menunjukkan tidak ada hubungan yang signifikan antara umur dan jumlah konsumsi rokok/hari dengan konsentrasi $\mathrm{CN}$ dalam urin. Kekuatan hubungan kedua variabel tersebut dengan konsentrasi $\mathrm{CN}$ dalam urin berturut-turut adalah sangat lemah dan lemah. Dengan demikian kontribusi umur dan jumlah konsumsi rokok/hari terhadap konsentrasi $\mathrm{CN}$ dalam urin masyarakat pesisir sangat kecil.

Tabel 4. Hasil Uji Regresi Linier Berganda Berbagai Faktor dengan Konsentrasi CN dalam Urin Masyarakat Pesisir

\begin{tabular}{|c|c|c|}
\hline Model & $\mathrm{B}$ & $p$-value \\
\hline (Constant) & $-11,426$ & 0,047 \\
\hline CN kerang & 33,662 & $\mathbf{0 , 0 2 3}$ \\
\hline Lama konsumsi kerang & 0,046 & 0,000 \\
\hline Singkong & 0,667 & 0,002 \\
\hline
\end{tabular}

Sumber: Data Primer, 2017

Tabel 4 hasil uji regresi linier berganda menunjukkan bahwa variabel independen yang menjadi prediktor terhadap konsentrasi $\mathrm{CN}$ dalam urin adalah konsentrasi $\mathrm{CN}$ dalam kerang hijau, lama konsumsi kerang hijau dan frekuensi konsumsi singkong dengan nilai $\mathrm{p}$ berturutturut $0.023,0.000$, dan 0,002 ( $\mathrm{p}<0,05$ ). 
Model regresi yang diperoleh adalah konsentrasi sianida dalam urin $(\mathrm{Y})=$ $11,426+33,662$ konsentrasi sianida dalam

\subsection{Pembahasan}

Sianida yang mengendap bersama dengan padatan tersuspensi mempengaruhi kualitas sedimen di dasar perairan dan juga perairan sekitarnya. Apabila partikulat memiliki massa jenis lebih besar dari massa jenis air laut maka partikulat akan mengendap di dasar laut atau terjadi proses sedimentasi (Salah et al., 2012). Penurunan kualitas perairan disekitar wilayah pesisir erat kaitannya dengan dengan penurunan kualitas biota yang hidup di perairan tersebut, termasuk kerang hijau (Sardar et al., 2013). Kerang hijau hidup di perairan payau hingga asin dan sifatnya menempel pada benda-benda yang ada di sekelilingnya, seperti kayu, bambu, badan kapal atau jaring tempat budidaya ikan (Jalius dkk., 2008). Penurunan kualitas kerang hijau akibat kontaminasi sianida berdampak pada manusia yang mengkonsumsinya. Hasil penelitian menunjukkan bahwa gangguan kesehatan yang dialami responden selama 3 bulan terakhir yaitu $70,0 \%$ mengalami mual dan muntah, 70,0\% vertigo, 60,0\% kehilangan napsu makan, 53,3\% sakit tenggorokan dan $83,3 \%$ gangguan penglihatan. Gangguan ini termasuk dalam gejala dan tanda dari keracunan sianida.

Berdasarkan hasil uji statistik diperoleh ada hubungan yang signifikan antara konsentrasi sianida dalam kerang hijau dengan konsentrasi sianida dalam urin $(\mathrm{p}=0,000)$ dan kekuatan hubungannya kuat $(\mathrm{r}=0,612)$. Kemungkinan ini dapat terjadi walaupun hasil pemeriksaan konsentrasi sianida rata-rata dalam kerang hijau masih sedikit di bawah ambang batas. Namun kerang hijau $\left(\mathrm{X}_{1}\right)+$ 0,046 lama konsumsi kerang hijau $\left(\mathrm{X}_{2}\right)+0,667$ frekuensi konsumsi singkong $\left(\mathrm{X}_{3}\right)$.

dampak dari akumulasi jangka panjang dapat saja terjadi. Konsentrasi sianida yang tinggi dalam urin responden selain dipengaruhi oleh pajanan oral, juga dipengaruhi oleh pajanan inhalasi seperti sianida yang menguap dari air laut. Hasil penelitian ini serupa dengan penelitian Birawida (2011), yang menjadikan kerang bakau yang tercemar nikel sebagai sumber pajanan dan kandungan nikel dalam urin masyarakat nelayan di Desa Tambea Binaan PT. Aneka Tambang Pomalaa, Kabupaten Kolaka Sulawesi Tenggara sebagai biomarkernya. Diperoleh hasil terdapat hubungan yang signifikan antara kandungan nikel dalam kerang bakau dengan kandungan nikel dalam urin.

Berdasarkan hasil uji statistik bahwa tidak ada hubungan yang signifikan antara umur dengan konsentrasi sianida dalam urin ( $\mathrm{p}=0,578)$ dan kekuatan hubungan yang sangat lemah $(r=-0,106)$. Hal ini karena tidak selalu responden yang berumur tua memiliki konsentrasi sianida dalam urin yang tinggi. Begitu pula sebaliknya, tidak selalu responden yang berumur muda memiliki konsentrasi sianida dalam urin yang rendah, sehingga nilai koefisien korelasi menunjukkan tanda negatif. Penelitian ini sama halnya dengan penelitian Anisah (2008), yang mengangkat variabel umur sebagai faktor risiko dan kadar merkuri dalam urin penambang emas di Kecamatan Kurun Kabupaten Gunung Mas Provinsi Kalimantan Tengah sebagai biomarkernya. Diperoleh hasil tidak ada hubungan yang signifikan antara umur dengan kadar merkuri dalam urin dengan $p$ value 0,078 . 
Berdasarkan hasil uji statistik diperoleh ada hubungan yang signifikan antara lama tinggal dengan konsentrasi sianida dalam urin $(\mathrm{p}=0,001)$. Kedua variabel memiliki hubungan yang cukup kuat $(r=0,594)$. Adanya hubungan yang signifikan antar kedua variabel tersebut karena responden tidak hanya terpajan oleh sianida yang dikonsumsi dari kerang hijau melainkan juga dari sianida yang menguap di perairan. Sianida yang dimaksud adalah sianida dalam bentuk asam sianida ( $\mathrm{HCN})$ yang mudah menguap pada suhu di atas suhu kamar yakni $26{ }^{\circ} \mathrm{C}$ (Isnaini, 2016). Penelitian sejenis yang dilakukan Anwar (2016), dengan menjadikan variabel lama tinggal sebagai faktor risiko dan kadar merkuri dalam urin masyarakat di Desa Tahi Ite Kabupaten Bombana sebagai biomarkernya. Diperoleh hasil ada hubungan antara lama tinggal dengan kadar merkuri dalam urin dengan nilai $\mathrm{p}=$ 0,001 ( $\mathrm{p}>0,05)$.

Berdasarkan hasil penelitian diperoleh bahwa ada hubungan yang signifikan antara lama konsumsi kerang hijau dengan konsentrasi sianida dalam urin $(\mathrm{p}=0,000)$. Kekuatan hubungan antar kedua variabel kuat $(r=0,703)$. Hal ini karena semakin lama seseorang mengkonsumsi kerang hijau yang terkontaminasi sianida maka semakin lama durasi mereka terpajan oleh sianida tersebut, sehingga memungkinkan semakin besar penyerapan sianida oleh tubuh manusia. Hasil penelitian ini serupa dengan penelitian Andri dkk (2011), dimana konsumsi ikan dijadikan sebagai sumber pajanan dan kadar merkuri pada rambut masyarakat di sekitar Penambangan Emas Tanpa Ijin sebagai indikator biologis pemantau zat pencemar dalam tubuh manusia. Diperoleh hasil yakni kebiasaan konsumsi ikan setempat terbukti sebagai faktor risiko kadar merkuri pada rambut melebihi ambang batas dengan nilai OR adjusted $=6,14$.

Berdasarkan hasil uji statistik diperoleh tidak ada hubungan yang signifikan antara jumlah konsumsi rokok/hari dengan konsentrasi sianida dalam urin $(\mathrm{p}=0,224)$. Kedua variabel tersebut memiliki kekuatan hubungan yang lemah $(r=0,229)$. Hal ini karena responden yang tidak merokok-pun memiliki konsentrasi sianida dalam urin yang tinggi, dengan kisaran 2,592 - 7,128 ppm. Variasi konsentrasi inilah yang memungkinkan tidak adanya hubungan yang signifikan antar kedua variabel. Hasil penelitian yang serupa dilakukan Suciani (2007), dengan mengambil kebiasaan merokok sebagai faktor risiko dan kadar $\mathrm{Pb}$ dalam darah polisi lalu lintas di jalan raya Kota Semarang sebagai biomarkernya. Diperoleh hasil tidak ada hubungan antara kebiasaan merokok dengan kadar $\mathrm{Pb}$ dalam darah.

Berdasarkan hasil uji statistik diperoleh ada hubungan yang signifikan antara frekuensi konsumsi singkong dengan konsentrasi sianida dalam urin $(\mathrm{p}=0,011)$. Kedua variabel memiliki hubungan yang cukup kuat $(\mathrm{r}=0,457)$. Semakin sering seseorang mengkonsumsi singkong tanpa melalui proses pengolahan terlebih dahulu, maka semakin besar penyerapan sianida oleh tubuh. Penelitian sejenis dilakukan di beberapa wilayah pesisir Malaysia. Frekuensi konsumsi ikan dijadikan sebagai faktor risiko dan kadar merkuri pada rambut sebagai biomarkernya. Penelitian tersebut menunjukkan frekuensi konsumsi ikan $>3$ kali/minggu berisiko meningkatkan kadar merkuri pada rambut masyarakat pesisir Malaysia yang melebihi ambang batas (Hajeb et al., 2008).

Pada umumnya sianida dalam bentuk glikosida sianogenik dapat terurai menjadi 
hidrogen sianida $(\mathrm{HCN})$ sehingga dapat dihilangkan dengan pencucian, perendaman, perebusan dan pengeringan selama proses produksi. HCN mempunyai sifat fisik mudah larut dalam air dan mempunyai titik didih $26{ }^{\circ} \mathrm{C}$. Oleh sebab itu, penurunan kandungan sianida pada produk singkong dikarenakan terjadi penguapan sianida bebas saat proses pengeringan dengan menggunakan pengering pada suhu $70^{\circ} \mathrm{C}$. Dengan pemilihan cara pengolahan yang tepat, kadar sianida pada bahan makanan dapat dikurangi sehingga menjadi aman untuk dikonsumsi (Sasongko, 2009).

\section{KESIMPULAN DAN SARAN}

Variabel yang berhubungan dengan konsentrasi sianida dalam urin masyarakat pesisir adalah konsentrasi sianida dalam kerang hijau, lama tinggal, lama konsumsi kerang hijau dan frekuensi konsumsi singkong sedangkan variabel yang tidak berhubungan yaitu umur dan jumlah konsumsi rokok/hari. Variabel yang menjadi prediktor terhadap konsentrasi sianida dalam urin adalah konsentrasi dalam kerang hijau, lama konsumsi kerang hijau dan frekuensi konsumsi singkong. Disarankan kepada masyarakat pesisir Desa Mallasoro untuk mengurangi atau bahkan tidak lagi mengkonsumsi kerang hijau dari perairan tersebut dan melakukan pengolahan yang tepat pada singkong sebelum dikonsumsi yakni dengan cara pencucian, perendaman atau perebusan, sehingga menjadi aman untuk dikonsumsi.

\section{UCAPAN TERIMA KASIH}

Ucapan terima kasih kepada Pemerintah Desa Mallasoro Kecamatan Bangkala Kabupaten Jeneponto Provinsi Sulawesi Selatan yang telah memberikan izin dan fasilitas kepada penulis dalam melakukan penelitian, serta kepada suluruh responden yang telah meluangkan waktunya selama penelitian berlangsung.

Penelitian ini telah memperoleh rekomendasi persetujuan etik dari Fakultas Kedokteran Universitas Hasanuddin Makassar Nomor: 507/H4.8.4.5.31/PP36KOMETIK/2017 Tanggal 18 Juli 2017 dengan nomor protokol UH17050378.

\section{DAFTAR PUSTAKA}

1. Andri D.H., Anies, \& Suharyo H. (2011). Kadar Merkuri pada Rambut Masyarakat di Sekitar Penambangan Emas Tanpa Ijin. Media Medika Indonesiana, 45(3): 181-187.

2. Anisah A. (2008). Faktor-faktor yang Berhubungan dengan Kadar Merkuri (Hg) dalam Urine pada Penambang Emas di Kecamatan Kurun Kabupaten Gunung Mas Provinsi Kalimantan Tengah Tahun 2008. (Abstrak). Semarang: Universitas Dian Nuswantoro.

3. Anwar. (2016). Analisis Hubungan Kandungan Merkuri (Hg) Pada Air Sumur Gali Terhadap Kesehatan MasyarakatDi Desa Tahi Ite Kabupaten Bombana. (Tesis). Makassar: Universitas Hasanuddin.

4. Birawida A.B. (2011). Analisis Kandungan Nikel (Ni) pada Sedimen Pantai dan Kerang Bakau (Polymesoda sp) Hubungannya dengan Kandungan Nikel (Ni) dalam Urine Masyarakat Nelayan Di Desa Tambea Binaan PT. Aneka Tambang Pomalaa, Kabupaten Kolaka Sulawesi Tenggara. J. Ecocelebica, 7(2): 129-135.

5. Cordoset al. (2003). Characterization of The Rivers System in The Mining and Industrial Area of Baia Mare, 
Romania. The European Journal of Mineral Processing and Environmental Protection, 3(3): 324-335.

6. Darmono.(2010). Lingkungan Hidup dan Pencemaran: Hubungannya dengan Toksikologi Senyawa Logam. Jakarta: UI-Press.

7. Dinas Kesehatan Provinsi Sulawesi Selatan. (2016). Laporan Hasil Penyelidikan Epidemiologi KLB Keracunan Pangan di Desa Mallasoro, Kecamatan Bangkala, Kabupaten Jeneponto Tanggal 31 Agustus s/d 3 September 2016. Provinsi Sulawesi Selatan.

8. Hajeb et al. (2008). Hair Mercury Level of Coastal Communities in Malaysia: a Linkage with Fish Consumption. Eur Food Res Technol, 227:1349-1355.

9. Ishak N.I. (2014). Analisis Risiko Logam Berat (Hg, Cd, As) pada Sedimen Laut, Ikan dan Kerang terhadap Kesehatan Masyarakat Pesisir Kota Makassar. (Tesis). Makassar: Universitas Hasanuddin.

10. Isnaini D. (2016). Sifat Fisika dan Kimia dari Sianida. Diakses 14 Juli 2017. Available from: https://www.scribd.com/doc/29654752 9/Sifat-Fisika-Dan-Kimia-Dari-

Sianida.

11. Jalius dkk. (2008). Akumulasi Logam Berat dan Pengaruhnya terhadap Spermatogenesis Kerang Hijau (Perna viridis). Jurnal Ilmu-ilmu Perairan dan Perikanan Indonesia, 15(1): 77-83.

12. Kamilah dkk. (2014). Keracunan Sianida. (Tugas Akhir). Pelembang: Universitas Sriwijaya.

13. Mangampe A., Daud A., \& Birawida A.B. (2014). Analisis Risiko Merkuri (Hg) dalam Ikan Kembung dan Kerang Darah pada Masyarakat di Wilayah
Pesisir Kota Makassar. (Skripsi). Makassar: Universitas Hasanuddin.

14. Ningtyias dkk. (2015). Makanan Mentah, Goitrogenik dan Gangguan Akibat Kekurangan Yodium (GAKY). Buletin Penelitian Sistem Kesehatan, 18(1): 105-110.

15. Oesch T.R. (2010). The Poisoned Planet, $2^{\text {nd }}$ Edition. United States of America: Xulon Press.

16. Salah et al. (2012). Assessment of Heavy Metals Pollution in The Sediments of Euphrates River, Iraq. Journal of Water Resource and Protection4:1009-1023.

17. Sardar et al.(2013). Heavy Metals Contamination and what are the Impacts on Living Organisms. Greener Journal of Environmental Management and Public Safety, 2(4): 172-179.

18. Sasongko P. (2009). Detoksifkasi Umbi Gadung (Dioscorea hispida Dennst) melalui Proses Fermentasi Menggunakan Kapang Mucor sp. Jurnal Teknologi Pertanian, 10(3): 205215.

19. Siagian L. (2012). Pengaruh Pencemaran Logam Berat Pb terhadap Biota Laut dan Konsumennya di Kelurahan Bagan Deli Belawan. Laporan Akhir Penelitian. Medan: Universitas HKBP Nommensen.

20. Siaka I.M. (2008). Korelasi antara Kedalaman Sedimen di Pelabuhan Benoa danKonsentrasi Logam Berat $\mathrm{Pb}$ dan $\mathrm{Cu}$. Jurnal Kimia 2(2): 61-70.

21. Simange S.M., Simbolon D., \& Jusadi D. (2010). Analisis Kandungan Merkuri (Hg) dan Sianida (CN) pada Beberapa Jenis Ikan Hasil Tangkapan Nelayan di Teluk Kao, Halmahera Utara. Jurnal Institut Pertanian Bogor: 335-353. 
22. Suciani S. (2007). Kadar Timbal dalam Darah Polisi Lalu Lintas dan Hubungannya dengan Kadar Hemoglobin (Studi Pada Polisi Lalu Lintas yang Bertugas di Jalan Raya Kota Semarang). (Tesis). Semarang: Universitas Diponegoro.

23. Susanty S.C. (2014). Kandungan Logam Berat $(\mathrm{Pb}, \mathrm{Cd}$, dan $\mathrm{Hg}$ ) pada
Kerang Bulu (Anadara antiquata) di Perairan Kronjo dan Cituis, Kabupaten Tangerang. (Skripsi). Bogor: Institut Pertanian Bogor.

24. Widowati W., Sastiono A., \& Jusuf R. (2008). Efek Toksik Logam: Pencegahan dan Penanggulangan Pencemaran. Yogyakarta: Penerbit Andi. 